\title{
Caso 4/2009 - Jovem de 14 Anos com Comunicação Interatrial e Estenose da Artéria Pulmonar Esquerda
}

Case 4/2009 - Fourteen-Year-Old Boy with Atrial Septal Defect and Left Pulmonary Artery Stenosis

Edmar Atik

Hospital Sírio Libanês, São Paulo, SP - Brasil

\section{Dados clínicos}

O sopro cardíaco havia sido auscultado pela primeira vez aos 4 meses de idade, por ocasião de uma broncopneumonia. Desde então, o paciente manteve-se assintomático, em franca atividade física e sem uso de medicação específica.

Ao exame físico o paciente estava em bom estado geral, eupnéico, sem cianose e com os pulsos normais. O peso era de 61,6 Kgs, a altura de $171 \mathrm{~cm}$, a frequência cardíaca de 80 bpm e a pressão arterial (PA) de 110/75 mm Hg. A aorta não era palpada na fúrcula, no precórdio havia impulsões discretas na borda esternal esquerda e o ictus cordis não era palpado. A segunda bulha era constantemente desdobrada, com os dois componentes iguais em intensidade. O sopro sistólico $+/++$ de intensidade, rude, de ejeção, era audível na borda esternal esquerda alta. Na área mitral, e em todo o dorso à esquerda, outro sopro sistólico, com timbre mais suave, era audível. O estalido protossistólico era evidente em toda a borda esternal e o fígado não era palpado.

O eletrocardiograma mostrava sinais de sobrecarga ventricular direita com onda R de $13 \mathrm{~mm}$ em V1. ÂQRS estava $\mathrm{a}+90^{\circ}, \hat{\mathrm{AP}} \mathrm{a}+70^{\circ}$ e $\hat{\mathrm{A} T} \mathrm{a}+60^{\circ}$.

\section{Imagem radiográfica}

Salienta a área cardíaca normal com nítido contraste da trama vascular pulmonar, diminuída à esquerda e aumentada à direita. $\mathrm{O}$ arco médio está retificado (figura 1).

\section{Impressão diagnóstica}

A imagem radiográfica é compatível com estenose da artéria pulmonar esquerda em face da diminuída vascularidade arterial desse lado. O aumento da vascularização pulmonar à direita pode sugerir desvio de sangue arteriovenoso, a nível atrial ou mesmo ventricular.

\section{Diagnóstico diferencial}

Cardiopatias acianogênicas com shunt de sangue da

\section{Palavras-chave}

Cardiopatias congênitas, Estenose supravalvar pulmonar, Septo interatrial / anormalidades, septo interatrial / cirurgia. esquerda para a direita tipo CIA/CIV/PCA, quando associadas à obstrução ao fluxo pulmonar, podem se apresentar dessa mesma maneira. A área cardíaca próxima do normal sugere o predomínio da lesão obstrutiva, mesmo em presença de comunicações intercavitárias de grande diâmetro.

\section{Confirmação diagnóstica}

Os dados clínicos orientaram ao diagnóstico de cardiopatia acianogênica com estenose da artéria pulmonar esquerda (sopro sistólico intenso no dorso, trama vascular pulmonar diminuída à esquerda e sobrecarga sistólica de ventrículo direito no eletrocardiograma) associada à comunicação interatrial pequena (discretas impulsões sistólicas na borda esternal e segunda bulha constantemente desdobrada). O ecocardiograma mostrou comunicação interatrial tipo ostium secundum de $10 \mathrm{~mm}$ de diâmetro, além da estenose no início da artéria pulmonar esquerda, com diâmetro de $5 \mathrm{~mm}$ e gradiente de pressão de $31 \mathrm{~mm} \mathrm{Hg}$. A perfusão pulmonar com tecnésio consolidou esse diagnóstico, através do fluxo pulmonar total de $94 \%$, sendo dirigidos $65 \%$ para o pulmão direito e $29 \%$ ao esquerdo.

\section{Conduta}

Na cirurgia, foi fechada uma comunicação interatrial ostium secundum de $12 \mathrm{~mm}$ de diâmetro, além de ampliada a artéria pulmonar esquerda estenótica com pericárdio autólogo. O paciente teve boa evolução com resolução do quadro anátomo-funcional.

\section{Comentário}

Em cardiopatias congênitas, detalhes radiográficos podem ser de grande valia diagnóstica, como no caso presente em que a trama vascular diminuída à esquerda tornou-se um elemento indiscutível da presença da estenose da artéria pulmonar esquerda. 


\section{Correlação Clínico-Radiográfica}



Fig. 1 - A imagem radiográfica mostra a área cardiaca próxima do normal, com discreta saliência do arco ventricular e com trama arterial pulmonar diminuída à esquerda, por presumivel estenose da artéria pulmonar esquerda.
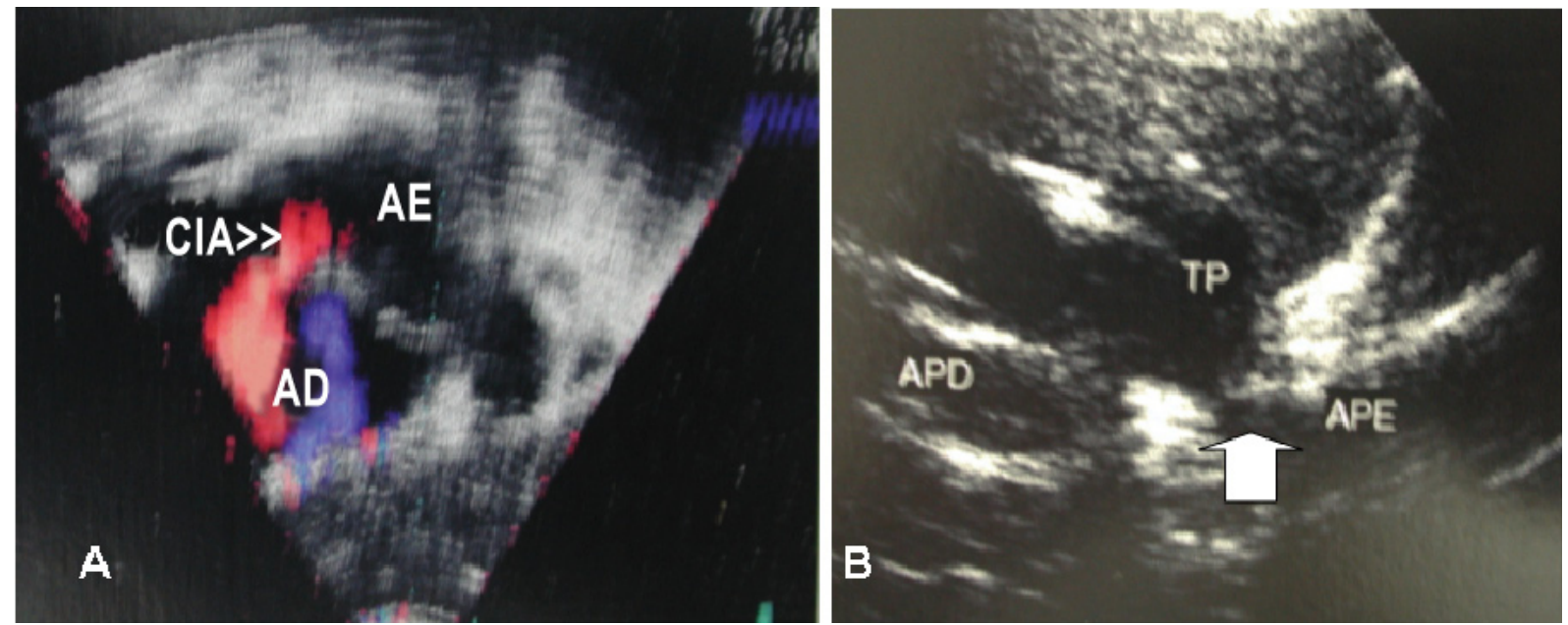

Fig. 2 - O ecocardiograma mostra o septo atrial com pequena descontinuidade e com fluxo, pelo color-Doppler, da esquerda para a direita, em corte subcostal, em A. Além disso, em corte paraesternal transverso, mostra a nítida estenose no início da artéria pulmonar esquerda (seta), em $B$. 